\title{
The influence of chromium as a diffusive additive in the boronizing treatment of AISI 4140 steel on the corrosion resistance of the coating evaluated by Electrochemical Impedance Spectroscopy (EIS)
}

\author{
Dimitrios I. Zagkliveris ${ }^{1,}{ }^{*}$, Azarias Mavropoulos ${ }^{2}$, Efstathios Ntovinos $^{1}$, Georgios K. \\ Triantafyllidis ${ }^{1}$ \\ ${ }^{1}$ Laboratory of Materials' Technology, Dept. of Chemical Engineering, Aristotle University of \\ Thessaloniki, 54124 Thessaloniki, Greece \\ ${ }^{2}$ Physical Metallurgy Laboratory, Dept. of Mechanical Engineering, Aristotle University of \\ Thessaloniki, 54124 Thessaloniki, Greece
}

\begin{abstract}
A large variety of protective coating is being used in industrial applications to improve the resistance of the metallic substrates against corrosion. The pack-cementation method for boronizing and borochromizing is effective to produce extremely hard and corrosion resistant thick coatings and, additionally, is a low-cost and simple technique. In the present study, AISI 4140 steel specimens underwent boronizing and afterwards chromizing by the pack-cementation method using $\mathrm{B}_{4} \mathrm{C}$ as boron source and $\mathrm{Fe}-\mathrm{Cr}$ as chromium source, respectively. In both treatments the appropriate activators were used. After chromizing the boronized substrate, a mixed boride phase $\mathrm{FeCrB}$ was formed, as it was confirmed by X-ray Diffractometry (XRD). The boronized and the borochromized specimens were subjected to Electrochemical Impedance Spectroscopy (EIS). From the analysis of the frequency response of the coating systems (Bode and Nyquist display), the conclusion that the borochromized specimens were significantly more corrosion resistant was extracted. Finally, data of optical and electron microscopy contribute to the validity of the conclusions.
\end{abstract}

\section{Introduction}

A plenty of technical applications demand the utilization of materials that withstand intense wear and corrosion conditions such as frictional contact with other hard components and interaction with corrosive environments, probably in a wide temperature range.

One of the mostly effective ways for superficial protection of many metallic materials against the above referred destructive conditions is the boronizing treatment. Boronizing is a thermochemical diffusion-dominant process, in which boron atoms diffuse into the crystal

*Corresponding author: zagklive@,cheng.auth.gr 
lattice of the base metal, which is usually steel [1] or a titanium alloy [2]. As a result, a superficial layer of one or more boride phases of the base metal are formed. In steels as base metals, the boride phases are $\mathrm{FeB}$ and $\mathrm{Fe}_{2} \mathrm{~B}$. Generally, the formation of a single-phase $\mathrm{Fe}_{2} \mathrm{~B}$ layer is desirable, because the presence of the $\mathrm{FeB}$ phase externally can lead to cracks due to the significantly lower thermal expansion coefficient and the internal stress agglomeration [3].

It is experimentally shown that the addition of another metallic element in the boride layer could result in an increase of the plasticity of the coating [4]. Another significant advantage, especially when chromium is used as additive, is the improvement of the resistance of the coating against corrosion [5].

The investigation of the borochromizing process as an optimized version of boronizing is an open field of research. In particular, experimental studies on chromizing a boronized steel (boronizing + chromizing) [6-8], boronizing a chromized steel (chromizing + boronizing) $[9,10]$ and the simultaneous borochromizing [11-13] are referred in the literature. In some of these cases, the examined property of the borochromized materials was resistance against friction [6,10] and the corrosion resistance [12].

In the present study, the boronizing + chromizing technique was selected as the most efficient against corrosion, as it was shown from a series of preliminary experiments and as it is confirmed in [5]. The borochromized specimens were tested in Electrochemical Impedance Spectroscopy (EIS) using an aqueous solution of $3 \mathrm{wt} . \% \mathrm{NaCl}$ as electrolyte. Their score in EIS method was compared with the simply boronized specimens. Both treatments were carried out by the pack-cementation technique. The last decade EIS became a valuable method for evaluating the corrosion resistance of boride [14] and other types of coatings on metallic materials [15-18].

\section{Materials \& methods}

In the preliminary stage of the study, specimens of AISI 4140 steel were boronized and then half of them underwent chromizing. Both thermochemical treatments were carried out using the pack cementation technique. The chemical composition of the AISI 4140 steel is presented in Table 1.

Table 1: Chemical composition of AISI 4140 steel

\begin{tabular}{|l|l|l|l|l|l|l|}
\hline Carbon & Silicon & Manganese & Chromium & Molybdenum & Phosphorus & Sulfur \\
\hline $0.38-0.43$ & $0.15-0.35$ & $0.75-1.00$ & $0.80-1.10$ & $0.15-0.25$ & $\leq 0.035$ & $\leq 0.040$ \\
\hline
\end{tabular}

The reacting powder which is used in boronizing treatment consisted of boron carbide $\left(\mathrm{B}_{4} \mathrm{C}, 230\right.$ mesh, Sigma-Aldrich), potassium tetrafluoroborate $\left(\mathrm{KBF}_{4}\right.$, powder, Alpha Aesar, $>99.5 \%$ ) and silicon carbide (SiC, 400 grit, Struers). Moreover, the chromizing powder consisted of ferrochrome (Fe, 325 mesh, Acros Organics, 99\% кal Cr, powder, Acros Organics, $>99 \%)$, ammonium chloride $\left(\mathrm{NH}_{4} \mathrm{Cl}\right.$, powder, Merck, 99.8\%) and aluminum oxide $\left(\mathrm{Al}_{2} \mathrm{O}_{3}\right.$, powder, Panreac, $\left.>99.5 \%\right)$. The composition and purpose of use of each component are presented in Table 2.

For the thermochemical treatments, a conventional CARBOLITE CWF 1300 furnace was used and the experiments were carried out in an argon atmosphere. After boronizing or borochromizing treatment, the specimens were examined with X-ray Diffractometry (XRD) with a BRUKER D8 device, scanning electron microscopy (SEM) with energy-dispersive X-ray spectroscopy capability (EDS) and finally with electrochemical impedance spectroscopy (EIS). 
Table 2: Experimental details of the boronizing and chromizing treatments

\begin{tabular}{|ccc|ccc|}
\hline \multicolumn{5}{|c|}{ Boronizing $\left(\mathbf{9 5 0}^{\circ} \mathrm{C}\right.$ for 8 h) } & \multicolumn{3}{c|}{ Chromizing $\left(\mathbf{1 0 5 0}^{\circ} \mathrm{C}\right.$ for $\left.\mathbf{6 ~ h}\right)$} \\
\hline \multicolumn{4}{c|}{ Powder composition } \\
\hline Component & Content $($ wt. $\%)$ & Purpose of use & Component & Content (wt.\%) & Purpose of use \\
\hline $\mathrm{SiC}$ & 80 & Filling material & $\mathrm{Al}_{2} \mathrm{O}_{3}$ & 69 & Filling material \\
\hline $\mathrm{B} 4 \mathrm{C}$ & 10 & Boron source & $\begin{array}{c}\mathrm{Fe}-\mathrm{Cr} \\
(50 / 50)\end{array}$ & 25 & $\begin{array}{c}\text { Chromium } \\
\text { source }\end{array}$ \\
\hline $\mathrm{KBF}_{4}$ & 10 & Activator & $\mathrm{NH}_{4} \mathrm{Cl}$ & 6 & Activator \\
\hline
\end{tabular}

\section{Results \& discussion}

\subsection{Boronizing \& borochromizing processes}

During the boronizing treatment, a compact dense single-phase $\mathrm{Fe}_{2} \mathrm{~B}$ coating was formed, as XRD measurements revealed (Figure 1). Also, a metallographic image of the coating is depicted in Figure 1a. One can observe that the coating layer displays the common "tooth"like morphology with the elongated crystallographically oriented (textured) $\mathrm{Fe}_{2} \mathrm{~B}$ monocrystallines.

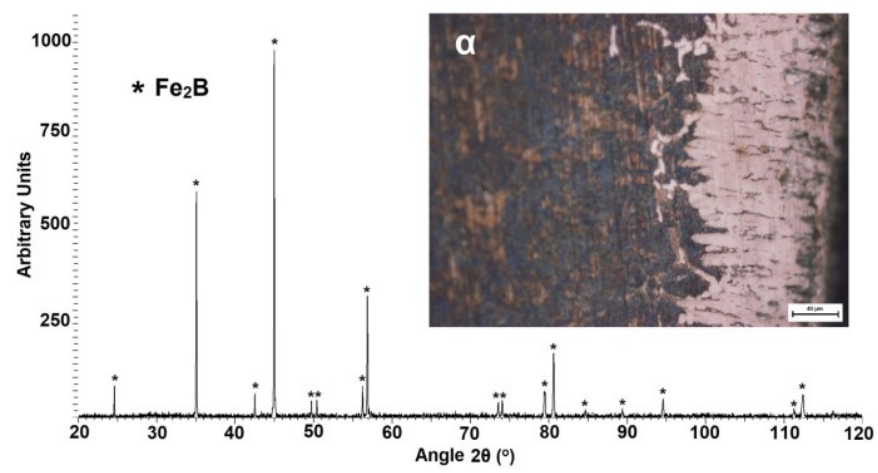

Figure 1: XRD spectrum and metallographic image of a boronized specimen

During the chromizing treatment, the previously formed $\mathrm{Fe}_{2} \mathrm{~B}$ phase was enriched with chromium up to half of its total thickness. As a result, an additional distinguishable borochromized layer appeared. Through XRD measurements the mixed boride phase $\mathrm{FeCrB}$ was recognized. Moreover, there is evidence of possible presence a chromium boride $\left(\mathrm{Cr}_{5} \mathrm{~B}_{3}\right)$ and traces of remaining elementary chromium (Figure 2).

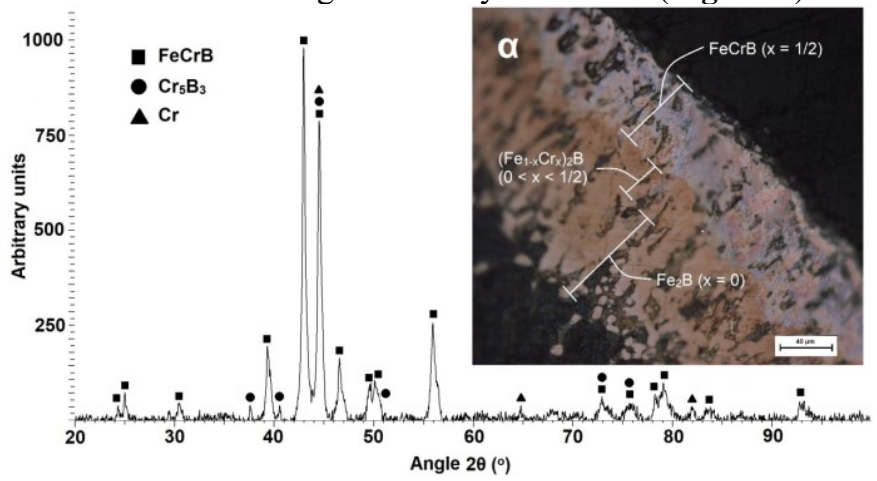

Figure 2: XRD spectrum and metallographic image of a borochromized specimen 
The mixed $\mathrm{FeCrB}$ phase is the result of chromium substitutional diffusion into the $\mathrm{Fe}_{2} \mathrm{~B}$ crystal lattice. $\mathrm{Cr}$ atoms are able to replace $\mathrm{Fe}$ atoms with a diffusional mechanism, when the necessary chemical potential difference is present. As the superficial FeCrB phase indicates, the $\mathrm{Cr} \rightarrow \mathrm{Fe}$ substitution has an approximately $50 \%$ efficiency close to the surface. However, deeper into the coating layer, the substitution rate decreases till nihilism. The chromium substitution rate gradient across the depth of the coating was determined by $\mathrm{SEM} / \mathrm{EDS}$ and is depicted in Figure 3.
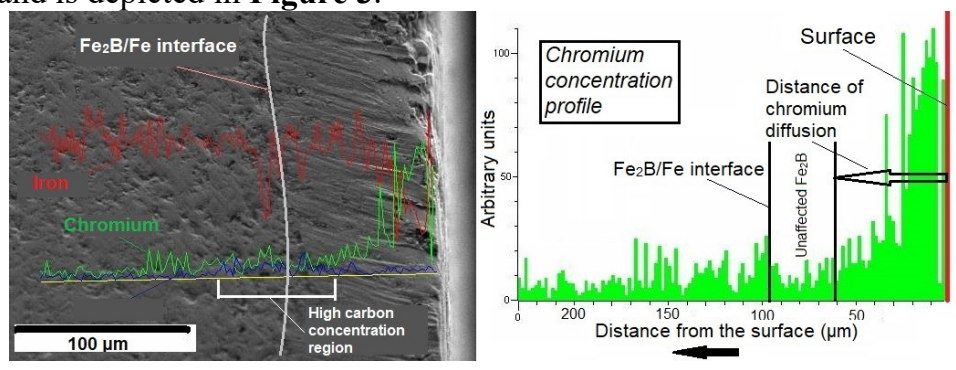

Figure 3: SEM/EDS analysis and chromium concentration profile of a borochromized specimen

The new chromium-modified $\mathrm{Fe}_{2} \mathrm{~B}$ coating can be formulated as: $\left(\mathrm{Fe}_{1-\mathrm{x}} \mathrm{Cr}_{\mathrm{x}}\right)_{2} \mathrm{~B}$ with $0 \leq x \leq 1 / 2$. The parameter $\mathrm{x}$ represents the chromium substitution rate, as it was described above. In accordance with this formula, when $\mathrm{x}=1 / 2$, the $\mathrm{FeCrB}$ phase results and, when $\mathrm{x}=$ 0 , the formula is simplified to the initial $\mathrm{Fe}_{2} \mathrm{~B}$ phase (Figure 2a). Additionally, as it is shown mainly in Figure 2a, the "tooth"-like morphology is significantly modified during the chromizing process. This is probably due to local boron diffusion phenomena, because of the high temperature of the chromizing treatment. This local diffusional mobility could lead to the decrease of the interface energy at the $\mathrm{Fe}_{2} \mathrm{~B} / \mathrm{Fe}$ interfaces. As an additional evidence of the local boron diffusion, the total thickness of the coating after chromizing is almost twice the thickness before (comparison between Figures 1 and 2), due to boron diffusion towards the metal substrate.

\subsection{Electrochemical Impedance Spectroscopy}

From the EIS experiments, data of real and imaginary part of impedance for each value of voltage frequency were collected. Bode and Nyquist diagrams were constructed, using these data (Figure 4).
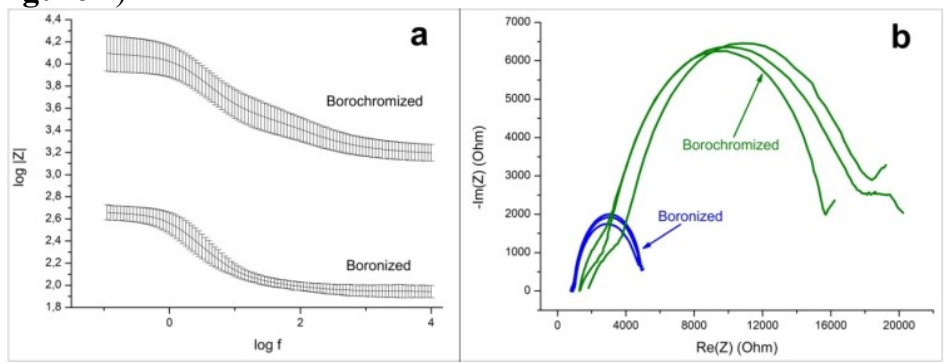

Figure 4: EIS analysis results. Bode (a) and Nyquist (b) diagrams

In Figure 4a, the depicted bands represent the statistical range of the measurements and the continuous line in the middle is the mean value. As it is obviously shown, the total impedance of the borochromized specimens (the $|\mathrm{Z}|$ in Bode diagram) is almost two orders of magnitude higher than the impedance of the boronized ones. This result leads to the safe 
conclusion that the chromizing treatment improves in a very high degree the impedance and, consequently, the corrosion resistance of the boride coating.

In full agreement with the Bode diagram, the significantly larger semicircular curves of the borochromized specimens in the Nyquist diagram (Figure 4b) indicate much higher ohmic resistance (real part of $\mathrm{Z}$ - $\mathrm{x}$-axis) as well as higher capacitive resistance (reactance) (imaginary part of $Z-y$-axis) in comparison with the boronized specimens.

The EIS data underwent an equivalent circuit fitting by using appropriate software. In Figure 5 the proposed equivalent circuits and the fitting results for two representative specimens are presented.
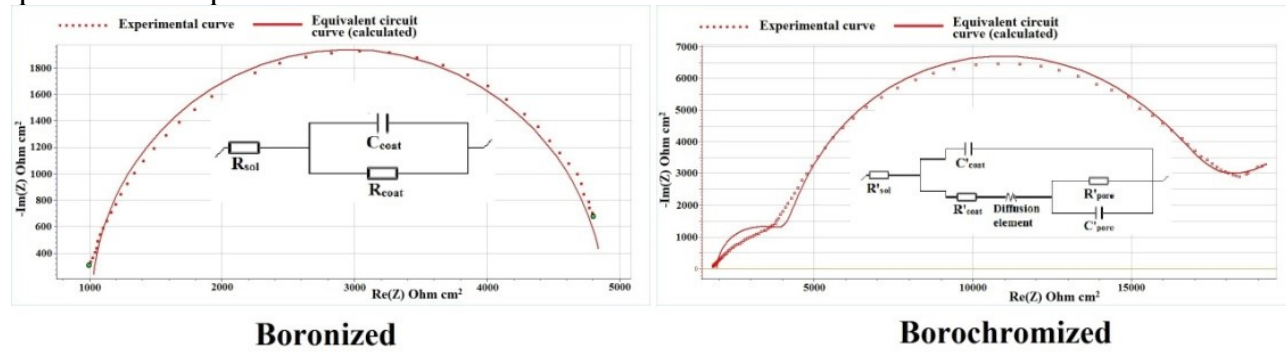

Borochromized

Figure 5: Equivalent circuits of the boronized and borochromized coatings

Both circuits consist of a main R-C loop, which corresponds to the coating's impedance $\left(\mathrm{R}_{\text {coat }}, \mathrm{C}_{\text {coat }}\right)$. Another common element is the ohmic resistance of the electrolyte solution $\left(\mathrm{R}_{\mathrm{sol}}\right)$. The experimental Nyquist diagram of the borochromized specimen (Figure 5b) consists of a small semicircle before the main one. This is attributed to the presence of pores with large tortuosity factor that can entrap corrosive substances in high concentration causing additional corrosion effect [14]. This pore system in the coating displays its own impedance and can be represented as a secondary $\mathrm{R}-\mathrm{C}$ loop in the equivalent circuit ( $\mathrm{R}_{\text {pore, }}$, $\mathrm{C}^{\prime}$ pore). Moreover, a diffusion electric element is been added in the borochromizing equivalent circuit in order to simulate the increase of the right side of the curve.

The results of the comparative study between the boronized and the borochromized coatings via EIS are ambiguous. On the one hand, the borochromized coatings represent very higher coating impedance than the boronized ones, which means that they display higher initial corrosion resistance. On the other hand, the presumptive pore network and the diffusion phenomena, that the borochromized coatings display, constitute risk factors for the evolution of their resistance levels after a significant time period in a corrosive environment.

\section{Conclusion}

- The boronizing process at $950^{\circ} \mathrm{C}$ for $8 \mathrm{~h}$ on AISI 4140 steel results in the formation of a dense single-phase $\mathrm{Fe}_{2} \mathrm{~B}$ coating layer with approximately $80 \mu \mathrm{m}$ thickness.

- When the boronized steel undergoes chromizing at $1050^{\circ} \mathrm{C}$ for $6 \mathrm{~h}$, an external layer of the mixed boride phase is formed and the total coating doubles in thickness.

- The Electrochemical Impedance Spectroscopy showed that chromizing improves to a great extent the resistance of the boronized steel against corrosion.

- Although, after chromizing, a possible superficial pore network, which can facilitate intense local galvanic corrosion and ion diffusion, could lead to a decrease of the durability of the borochromized coating through time. These phenomena are absent from the simple boride coatings. 
The authors would like to thank prof. Eleni Pavlidou (Dept. of Physics, A.U.Th.) for conducting SEM/EDS measurements and Ms. Xanthi Dabou for her contribution at XRD experiments.

This study was financially supported by General Secretariat of Research and Technology (GSRT) and Hellenic Foundation for Research and Innovation (HFRI) (Grant No: 530).

\section{References}

1. A.G. Matuschka, Boronizing, (Carl Hanser-Verlag, Munchen, 1978)

2. W. Fichtl, Mater. Des. 2 276-286 (1981)

3. M. Rile, Met. Sci. Heat Treat. 16 836-838 (1974)

4. J.R. Davis, Surface Hardening of Steels: Understanding the Basics, ed. J.R. Davis, (ASM International) 213-223.

5. P.A. Dearnley and T. Bell, Surf. Eng. 1 203-217 (1985)

6. S. Sen and U. Sen, Ind. Lubr. Tribol. 6 146-153 (2009)

7. S. V. Grachev, L. A. Maltseva, T. V. Maltseva, A. S. Kolpakov, and M. Yu. Dmitriev, Met. Sci. Heat Treat. 41 465-468 (1999)

8. Yu. A. Balandin, Met. Sci. Heat Treat. 47 103-106 (2005)

9. V. V. Shyrokov, Kh. B. Vasyliv, L. A. Arendar, and E. M. Rudkovskyi, Mater. Sci. 46 440-447 (2011)

10. V. Samadi and A. Habibolahzade, Mater. Sci. Technol. 26 41-46 (2010)

11. Suwattananont N. Solid State Sci. 14 1669-1672 (2012)

12. N. Suwattananont and R. Petrova, Solid State Sci. 14 1669-1672 (2012)

13. S. M. Chernega, Ya. V. Zaulichnyi, M. V. Karpets, and M. V. Belous, Powder Metall. Met. Ceram. 39 594-598 (2000)

14. I. Campos, M. Palomar-Pardave, A. Amador, C. V. Velazquez, and J. Hadad, Appl. Surf. Sci. 253 9061-9066 (2007)

15. B. R. Hinderliter, S. G. Croll, D. E. Tallman, Q. Su, and G. P. Bierwagen, Electrochim. Acta, 51 4505-4515 (2006)

16. S. J. Cooper, A. Bertei, D. P. Finegan, and N. P. Brandon, Electrochim. Acta 251 681689 (2017)

17. S. J. Lee and S.I. Pyun, J. Solid State Electrochem., 11 829-839 (2007)

18. S. Skale, V. Dolecek, and M. Slemnik, Corros. Sci. 49 1045-1055 (2007) 